\title{
Joining of Incompatible Polymer Combinations by Form Fit Using the Vibration Welding Process
}

\author{
Michael Wolf, Tobias Kleffel, Christoph Leisen, and Dietmar Drummer \\ Friedrich-Alexander-University (FAU), Institute of Polymer Technology, Am Weichselgarten 9, 91058 Erlangen, Germany \\ Correspondence should be addressed to Michael Wolf; wolf@lkt.uni-erlangen.de
}

Received 29 May 2017; Accepted 1 August 2017; Published 5 September 2017

Academic Editor: Eliane Espuche

Copyright ( 2017 Michael Wolf et al. This is an open access article distributed under the Creative Commons Attribution License, which permits unrestricted use, distribution, and reproduction in any medium, provided the original work is properly cited.

\begin{abstract}
The production of components consisting of various polymer types by welding is severely restricted and only possible for bonding compatible materials with melting points in a close range. Several modifications, such as the cross-linking of one joining partner, allow for circumventing the restrictions regarding the melting points but do not help in joining bonding incompatible materials. Investigations of dissimilar material combinations, especially from polymer-metal hybrid structures, show a high potential of connections based on form fits. Within the scope of this paper, the possibility of joining incompatible polymer combinations, such as polyamide 66 and high-density polyethylene, by micro form fit using the vibration welding process is analyzed. For this purpose, the generated bonding strength of the test specimen was determined by shear tests. Furthermore, the undercuts of the generated prestructures and the resulting bond of the test specimen were examined microscopically by computer-tomography. These investigations depict the high potential of joining incompatible polymer combinations by form fit in the vibration welding using prestructuring to generate undercuts.
\end{abstract}

\section{Introduction}

In order to increase the functionality of components, for example, in the automotive industry, it is often necessary to combine various polymer types. Otherwise, it is usually not possible to satisfy different requirements in media resistance, mechanical properties, and so on [1]. Such multimaterial combinations are particularly challenging for joining technologies with short cycle times, like welding [2]. For the creation of a bond between different polymers using welding technologies, a bonding compatibility of them is necessary [3-5]. This greatly restricts the material selection for these welding technologies. An overview of bonding compatible polymers which can form adhesion to each other is provided for joining technologies by Rotheiser [6] and, for the example of multicomponent injection molding, by Jaeger [7]. Furthermore, an approximately equal melting (semicrystalline thermoplastic) or softening temperature (amorphous thermoplastic) is required for the production of multimaterial joints by friction based welding [5]. The temperature in the joining zone usually does not increase by more than $10-20 \mathrm{~K}$ above the melting or softening temperature of the lower-melting component $[5,8,9]$. Menacher was able to show that a cross-linking of the material allows for a joining of polymers with different melting points, for example, high performance thermoplastics with standard thermoplastics, by vibration welding [10]. Nevertheless, the radiation crosslinking is an additional and time-intensive process step, which usually cannot be run in-house.

Investigations of dissimilar material combinations, especially from the field of polymer-metal hybrid structures, show a high potential of connections based on or provided by form fits. Such form fits are produced microscopically or macroscopically on the metal component, for example, with laser structuring [11-14], corundum blasting $[15,16]$, pickling [16], or by electrochemical treatments [17]. Thus, the aim was to transfer this strategy of joining polymer-metal hybrid structures by form fits to polymer-polymer joints by using existing joining technologies with short cycle times.

Here, the friction based vibration welding process shows a particularly high suitability. In addition to the short cycle times, vibration welding is also characterized by a high process flexibility and stability, energy efficiency, and high reproducibility. Compared to other joining methods, there is 


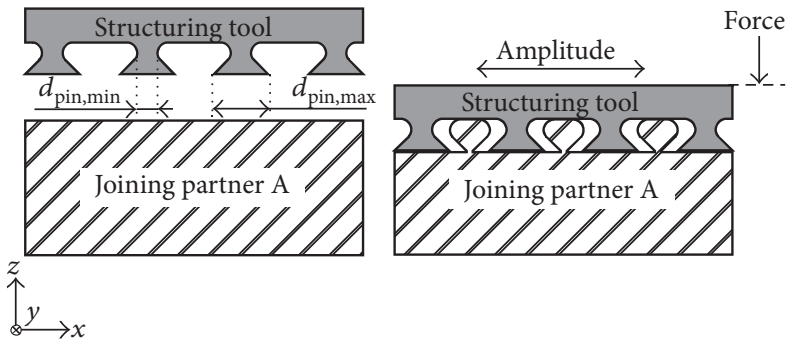

(a)

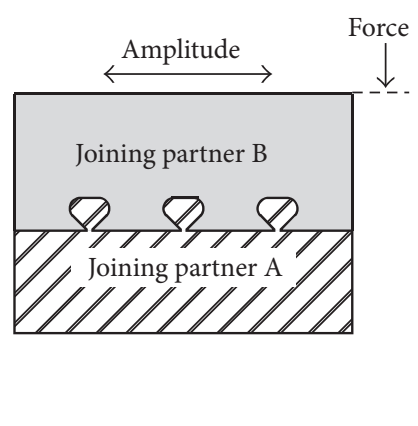

(b)

FIgURE 1: Process idea of joining incompatible polymer combinations by form fit using the vibration welding process. (a) Prestructuring process of joining partner A. (b) Welding process of joining partner A and joining partner B.

also no introduction of a foreign material [18]. The process principle of vibration welding is based on a friction-relative movement between the joining parts [3, 19]. During this movement, the parts are pressed together [18]. After a short time, the polymer melts at the contact surface and a melt film depending on the joining pressure is formed $[18,20]$. After the end of the friction-relative movement, the joining parts are held together under a defined pressure until the joining area is cooled sufficiently and the material is frozen $[5,18]$. The resulting weld strength is mainly depending on the joining pressure. A changing amplitude changes the resulting temperature profile in the melting layer but has only a small influence on the mechanical weld strength [20].

\section{Materials and Methods}

2.1. Schematically Process Idea. The idea of joining incompatible multimaterial combinations is based on adhesion by form fit. The bonding belongs to a prestructuring of joining partner $\mathrm{A}$, which generates undercuts directly during the vibration welding process and a subsequent joining of the prestructured joining partner $\mathrm{A}$ with the joining partner $\mathrm{B}$ by using the same process, Figure 1 . The joining partner A should have a significantly higher melting temperature than the joining partner B. This ensures a dimensional stability of the inserted prestructures of the joining partner A while the joining partner B is molten and can fill these structures. Other strategies for achieving a shape stability of the embedded prestructures, such as, for example, cross-linking, are also conceivable, if there is no sufficient difference in the melting points.

At the beginning of the process, the high-melting joining partner A (in our research polyamide 66) and the structuring tool with a defined structure are inserted into the vibration welding system. By means of a defined joining pressure and amplitude, the prestructure is formed into the joining partner A, Figure 1(a). In this case, the joining path should correspond approximately to the structural height of the structuring tool. When the desired welding depth is reached, the vibrational movement stops and the structuring tool is moved upwards out of the still molten polymer. As the oscillating head is moved by a magnet, this head always remains in the center position of the oscillating path at the end of the vibrational movement. This ensures that the undercuts are not destroyed when moving the structuring plate in $z$-direction, if the sum of the minimum pin width in $x$-direction $\left(d_{\text {pin,min }}\right)$ and the amplitude a is equal to or greater than the maximum pin width in $x$-direction $\left(d_{\text {pin,max }}\right.$; compare Figure 1):

$$
d_{\mathrm{pin}, \min }+a \geq d_{\mathrm{pin}, \max }
$$

In a following step, the structuring tool is exchanged with the joining partner B (high-density polyethylene for our investigations). Afterwards, the conventional vibration welding takes place, Figure 1(b). The joining partners perform a frictional-relative movement to one another; the lowermelting joining partner $\mathrm{B}$ melts in the joining zone and fills the prestructures of the joining partner A under a defined joining pressure. Actual limitation of the necessity of similar melting temperatures of both materials for the welding process represents advantages for the joining based on prestructuring. Due to the fact that the temperature in the joining zone rises to values not more than $20 \mathrm{~K}$ above the melting temperature of the lower-melting joining partner $\mathrm{B}[5,8,9]$, the structures of the joining partner A remain dimensionally stable when a sufficient difference between the melting points of the two polymers exists. Therefore, the melting point of the joining partner A ( $\left.T_{M \text {,Joining Partner A }}\right)$ should be clearly above the melting point of the joining partner B ( $\left.T_{M \text {,Joining Partner B }}\right)$ plus $20 \mathrm{~K}$ :

$$
T_{M \text {,Joining Partner A }} \gg T_{M \text {,Joining Partner B }}+20 \mathrm{~K} \text {. }
$$

Depending on the choice of the process parameters, a more or less complete filling of the prestructures, especially of the undercuts, takes place. After reaching a selected welding depth, which should approximately correspond to the prestructure depth, the welding process is terminated and the cooling takes place under a defined holding pressure.

2.2. Materials. For our research, a commercially available polyamide 66 (PA66), type Durethan A30S (Lanxess Deutschland $\mathrm{GmbH}$, Germany, Cologne) was used as joining partner A and structured with the structuring tool. As joining partner $\mathrm{B}$, an also commercially available high-density 
TABLE 1: Process parameter of injection molding process.

\begin{tabular}{|c|c|c|c|c|c|}
\hline Material & $\begin{array}{l}\text { Temperature profile } \\
\text { Screw } \rightarrow \text { nozzle }\left[{ }^{\circ} \mathrm{C}\right]\end{array}$ & $\begin{array}{c}\text { Mold } \\
\text { temperature } \\
{\left[{ }^{\circ} \mathrm{C}\right]} \\
\end{array}$ & $\begin{array}{c}\text { Injection } \\
\text { speed }[\mathrm{mm} / \mathrm{s}]\end{array}$ & $\begin{array}{c}\text { Holding } \\
\text { pressure [bar] }\end{array}$ & $\begin{array}{c}\text { Holding } \\
\text { pressure time } \\
{[\mathrm{s}]}\end{array}$ \\
\hline PA66 & $250 / 260 / 270 / 280 / 280$ & 80 & 50 & 500 & 30 \\
\hline HDPE & $200 / 210 / 220 / 230 / 240$ & 50 & 50 & 500 & 45 \\
\hline
\end{tabular}

TABLE 2: Parameter settings of prestructuring process.

\begin{tabular}{lcccc}
\hline Welding partners & Amplitude $[\mathrm{mm}]$ & Joining pressure $\left[\mathrm{N} / \mathrm{mm}^{2}\right]$ & Welding time $[\mathrm{s}]$ & Holding time $[\mathrm{s}]$ \\
\hline Structuring tool/PA66 & 0.6 & 6.5 & 18 & 0 \\
\hline
\end{tabular}

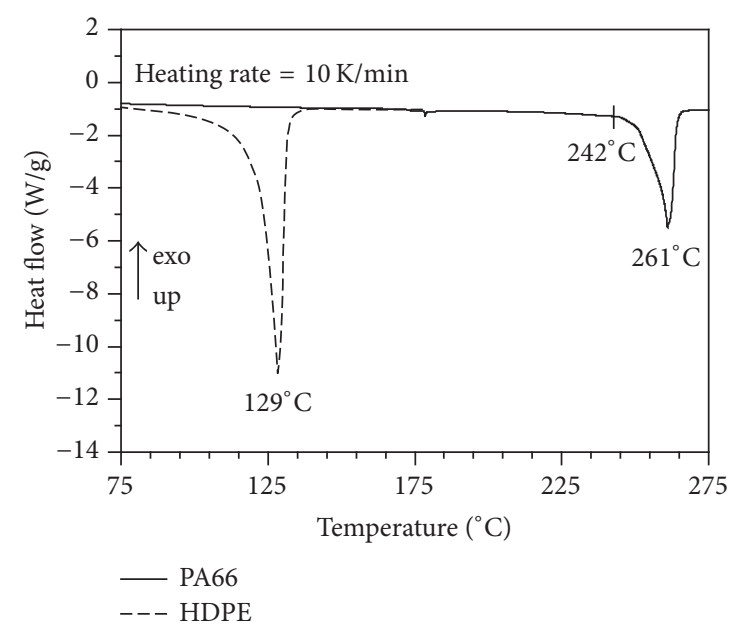

FIgURe 2: Melting behavior of the PA66 and the HDPE joining partner.

polyethylene (HDPE) type Lupolen 4261 (LyondellBasell Industries N.V., Netherlands, Rotterdam) was selected. Before the manufacturing process, the PA66 granular was dried at $80^{\circ} \mathrm{C}$ for $12 \mathrm{~h}$.

The melting behavior of both materials was analyzed with DSC measurements $(3 \mathrm{mg}$ samples, $10 \mathrm{~K} / \mathrm{min}$ heating rate; DSC Q 2000 (TA Instruments, US, New Castle)) as shown in Figure 2. The HDPE exhibits a melting peak temperature of about $129^{\circ} \mathrm{C}$, whereas the melting peak of the PA66 is located at a temperature of $261^{\circ} \mathrm{C}$. The difference of the melting peak temperatures between both materials is $132 \mathrm{~K}$. A softening of the material can take place from the onset of the melting peak on and hence dimensional stability may no longer be given which is the case for temperatures above $242^{\circ} \mathrm{C}$ for the used PA66. The difference between the melting peak temperature of the HDPE and the onset temperature of the PA66 is measured to $113 \mathrm{~K}$. In consequence, the onset temperature of the PA66 significantly exceeds the maximum temperature in the joining zone of approximately $20 \mathrm{~K}$ above the melting peak temperature of the low-melting polymer $[8,9]$. Thus, a melting of the generated pin structures can be excluded and dimensional stability can be assumed.

The structuring tool for prestructuring the joining partner A was made of structural steel, type S235JR, and subsequently hardened in order to avoid the wear of the structures.

\subsection{Experimental Procedure}

2.3.1. Joining Partners. Plates with a geometrical dimension of $150 \mathrm{~mm} \times 68 \mathrm{~mm} \times 4 \mathrm{~mm}$ were manufactured via injection molding using an injection molding machine Allrounder 370V/800-315 (Arburg, Germany, Loßburg). The joining samples with the dimension of $70 \mathrm{~mm} \times 50 \mathrm{~mm} \times 4 \mathrm{~mm}$ were milled out of these plates. An extract of the used injection molding parameters for the PA66 and HDPE joining partners is given in Table 1.

2.3.2. Structuring Tool. The structuring tool, which was used for the prestructuring of the joining partner A, was milled out of a steel plate and had the dimension of $70 \mathrm{~mm} \times 50 \mathrm{~mm}$ $\times 4 \mathrm{~mm}$. On one side of the structuring tool, four rows with pin structures are located, consisting of 16 pins. Thus, the patterning surface features 64 pins which allows for the double number of undercut structures (two undercut sections per pin). The height of the pin structures is $1.75 \mathrm{~mm}$ which results from initial drillings with a diameter of $2.0 \mathrm{~mm}$ and a subsequent milling by a depth of $0.25 \mathrm{~mm}$. The individual pins are spaced approximately $3 \mathrm{~mm}$ apart. The pin rows are separated by a $2.0 \mathrm{~mm}$ wide groove produced by milling. Figure 3 shows the pin based structuring tool which was used for the prestructuring and the inserting of the undercuts into the PA66.

2.3.3. Prestructuring of Joining Partner A. The prestructuring of joining partner A, in this study PA66, was performed on a Branson 2800 linear vibration welding machine (Branson Ultraschall, EMERSON Technologies GmbH \& Co. OHG, Germany, Dietzenbach). The welding machine is equipped with an oscillation driver system, type M-522 H, with highly dynamic amplitude control. The system works with an amplitude up to $0.9 \mathrm{~mm}$ at a nominal resonance frequency of $240 \mathrm{~Hz}$. For prestructuring of joining partner A, the structuring tool was vibrated into the PA66 plate with an amplitude of $0.6 \mathrm{~mm}$ and a joining pressure of $6.5 \mathrm{~N} / \mathrm{mm}^{2}$ for a time of $18 \mathrm{~s}$, Table 2 . A holding time to cool down the molten PA66 was not implemented; the structuring tool was moved out of the specimen directly after the end of vibration.

2.3.4. Vibration Welding. The welding tests were carried out after the prestructuring process. The same vibration welding machine was used for this purpose; only the structuring 
TABLE 3: Parameter settings of vibration welding process.

\begin{tabular}{lcccc}
\hline Welding partners & Amplitude $[\mathrm{mm}]$ & Joining pressure $\left[\mathrm{N} / \mathrm{mm}^{2}\right]$ & Welding time $[\mathrm{s}]$ & Holding time $[\mathrm{s}]$ \\
\hline PA66 prestructured/HDPE & 0.6 & 2.0 & 15 & 15 \\
PA66 unstructured/HDPE & 0.6 & $1.0 / 2.0 / 3.0$ & 15 & 15 \\
\hline
\end{tabular}
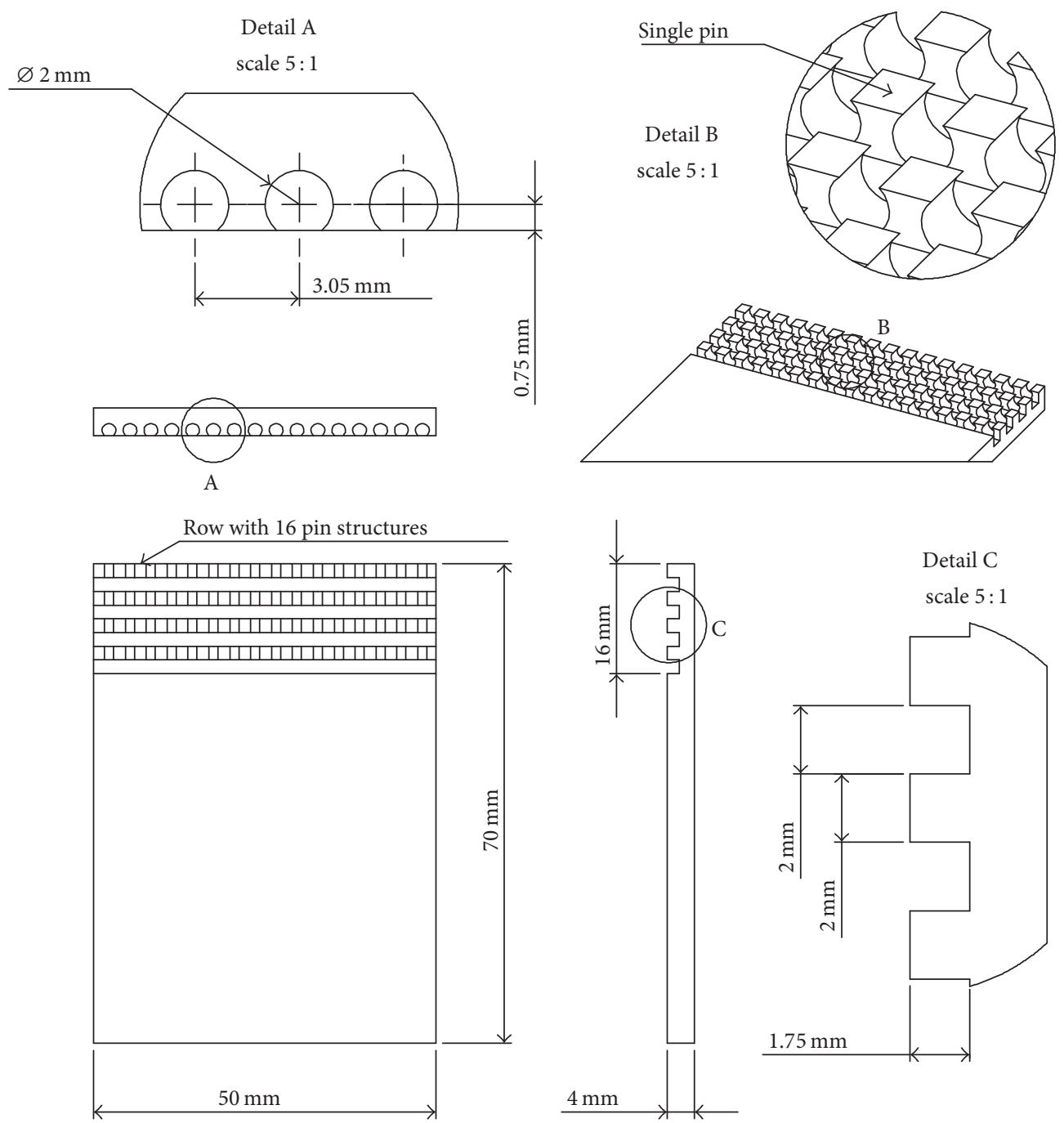

FIGURE 3: Geometrical dimensions of the used structuring tool with 64 pin structures involving undercut areas.

tool was exchanged with the joining partner $\mathrm{B}$, for this investigation HDPE. The prestructured joining partner A remained in the machine. In the vibration welding tests, an amplitude of $0.6 \mathrm{~mm}$ with a joining pressure of $2.0 \mathrm{~N} / \mathrm{mm}^{2}$ and a welding time of $15 \mathrm{~s}$ were chosen, Table 3 . The holding time was set to $15 \mathrm{~s}$ with a holding pressure equal to the joining pressure. The overlap length of the lap-joints was designed in such a way that the undercut structures of three pin rows ensure the bonding based on form fit between the two polymers, Figure 4. Therefore, a total number of 48 pins or rather 96 undercut sections are used for the interlocking connection. The use of three out of four pin rows is due to further structuring tools which only contain three pin rows and should be considered in additional investigations.
In addition to the welding tests with prestructured PA66 joining partners, unstructured PA66 and HDPE plates were joined by vibration welding. The parameters were chosen according to the previous experiments, Table 3 . In addition, tests with a joining pressure of 1.0 and $3.0 \mathrm{~N} / \mathrm{mm}^{2}$ were made. The joining pressure was varied to exclude an influence of the pressure on the incompatibility of the used polymers in the welding process.

\subsection{Analysis Methods}

2.4.1. Computer-Tomography (CT). The CT analyses were done with a micro-radiography-computer-tomograph device, type sub $\mu$-CT (Fraunhofer Institute for Integrated Circuits (IIS) e.V., Germany, Erlangen). The measurements were 


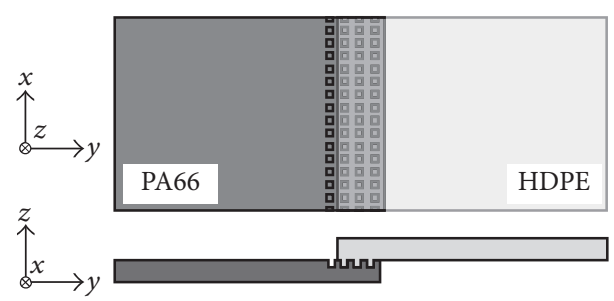

FIGURE 4: Overlap geometry of the vibration welding test specimen consisting of prestructured joining partner A (PA66) and joining partner B (HDPE).

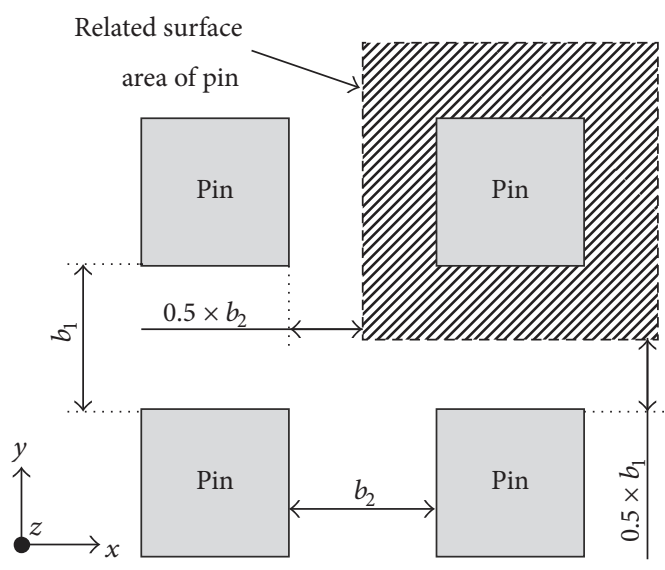

FIgURE 5: Definition of related surface area of the pins.

done on the whole test specimen and, in order to enable a higher resolution of the joining zone, also on cubes with a dimension of approximately $8 \mathrm{~mm} \times 8 \mathrm{~mm} \times 8 \mathrm{~mm}$ prepared out of the produced test specimens.

2.4.2. Mechanical Test: Shear Test. For the shear tests, a universal testing machine with computer-controlled test executions, type Zwick 1474 (Zwick GmbH \& Co. KG, Germany, Ulm) was used. Each test was performed under standard conditions according to DIN EN ISO $219\left(T=23^{\circ} \mathrm{C}\right.$, relative air humidity: $50 \%$ ) with a pull-off speed of $1 \mathrm{~mm} / \mathrm{min}$. Before testing, the specimens were stored dry in a vacuum furnace at $23^{\circ} \mathrm{C}$. The tensile force and strain as well as the force at failure for 10 samples were recorded. The tensile force per single pin and its related surface area, seen in Figure 5, is calculated by division of the measured force by the number of generated pins.

The performed shear tests serve as proof of concept and allow a first assessment of the potential of the joint based on form fit. As a result of the construction of the single lap test specimen, there is a bending moment $M_{b}$ during the test, which leads to a load outside of the joining surface, Figure 6 . Without a resulting undercut in $z$-direction, a failure of the test specimen would occur by a simple release of the pins without an application of a relevant bond strength.

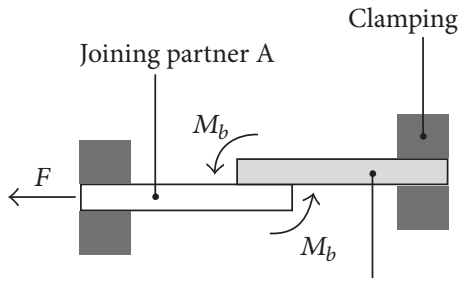

Joining partner B

FIGURE 6: Loads on a single lap test specimen during the test.

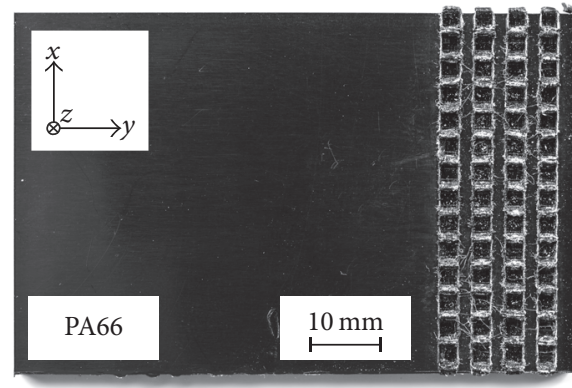

FIGURE 7: Photography of the prestructured joining partner A (PA66) with generated undercuts.

\section{Results and Discussion}

\subsection{Joining Process}

3.1.1. Prestructuring Process. The prestructured joining partner A (PA66), Figure 7, shows a negative image of the pin rows of the structuring tool and thus undercut structures. The generated prestructure and the undercut areas can be seen in the computer-tomography tests, Figure 8 . The undercuts are mainly located in the lower half of the pin structures which accords to the geometry of the structuring tool. The structure height of the pins extends over the entire area in the range between 1.7 and $1.9 \mathrm{~mm}$, exemplarily shown in the illustrated section (Figure 8). The height of the prestructures corresponds relatively well to the pin geometry of the structuring tool, which has a height of $1.75 \mathrm{~mm}$. The slight height deviations can be explained by the extraction of the structuring tool out of the still molten polymer. In this case, a slight deformation of the prestructures can take place.

3.1.2. Vibration Welding. The welding tests were carried out for the manufacturing of single lap test specimens. A lateral view in $x$-direction of the joining zone shows that the prestructures were filled during the vibration welding process by the molten HDPE material. The computer-tomography tests show a complete filling of the previously inserted structures across the entire joining area, Figure 9(a). In accordance with the plain prestructures, the polymer joint shows areas with undercuts. By filling these undercuts with vibration welding, areas are generated which cause a bonding by means of a form fit in $z$-direction, Figure 9(b). In addition, a form fit in $x$-direction occurs by a complete filling of the space 


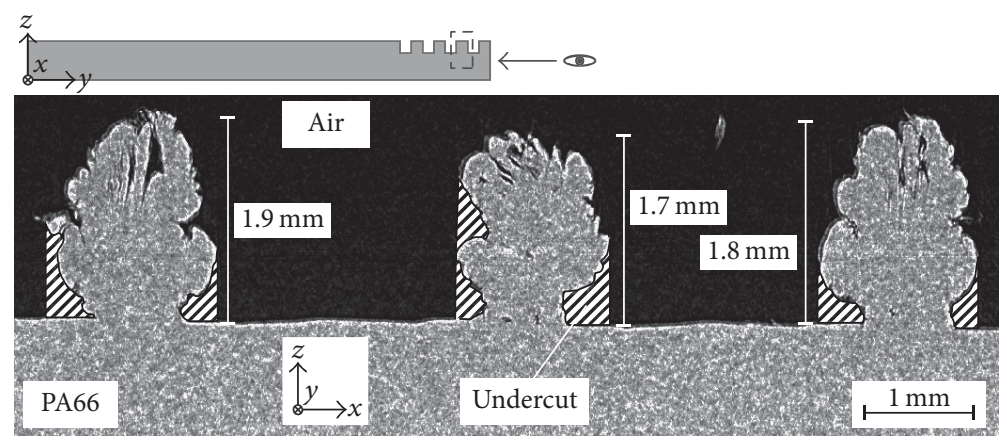

FIGURE 8: CT image of prestructured joining partner A (PA66) with generated undercuts.

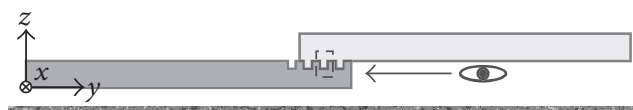

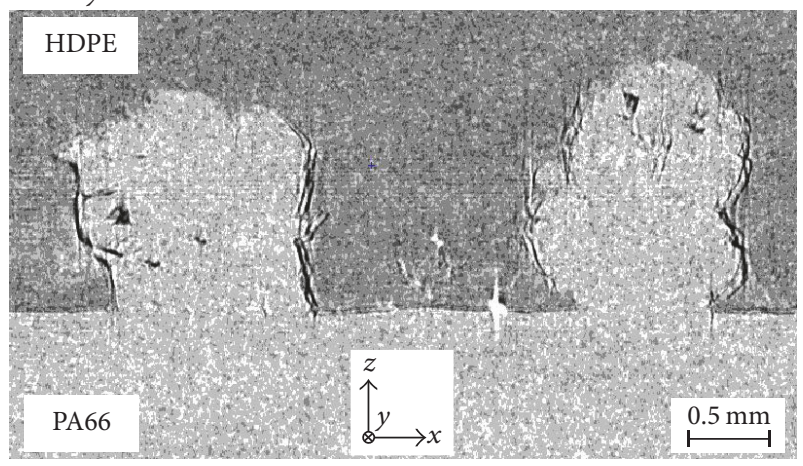

(a) Filled prestructures of joining partner A (PA66) vibration welded with joining partner B (HDPE)

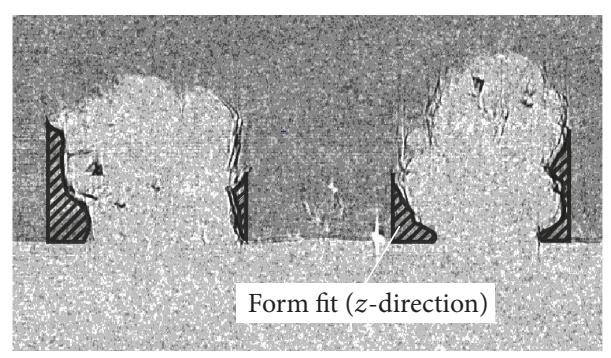

(b) Resulting form fit area of test specimen in $z$ direction

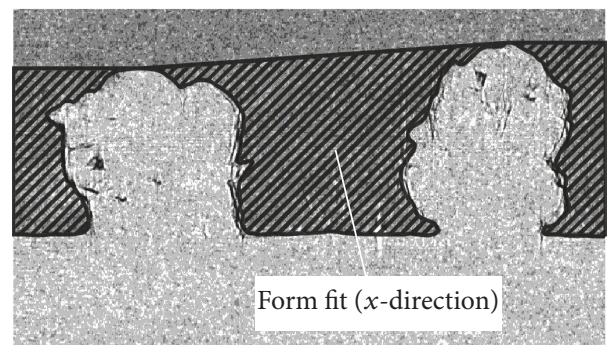

(c) Resulting form fit area of test specimen in $x$ direction

FIGURE 9: CT image of PA66-HDPE test specimen, produced by prestructuring and subsequent vibration welding.

between the pins in $z$-direction, Figure 9(c). In comparison to the conventional welding trials which resulted in immediate failure of the joint during handling, the structure based joint of the incompatible polymers PA66 and HDPE is more resilient.

3.2. Failure Behavior: Tensile Force. The tensile force to displacement relationship is shown in Figure 10 for each sample individually. A nearly identical curve progression can be seen up to a tensile force of about $2000 \mathrm{~N}$. The maximum tensile force attained by a single test specimen is $2350 \mathrm{~N}$; the average is located at $2147 \pm 123 \mathrm{~N}$. For a single pin and its related surface area an average tensile force of $45 \pm 3 \mathrm{~N}$ results. Due to the nonmeasurable bonding strength of unstructured specimens, it can be assumed that solely the pins and their existing form closure cause the bonding strength. The surrounding surface area probably has a negligibly small influence on the bonding strength.

Predominantly, adhesive failure behavior by the release of the form fit from the undercuts could be observed, Figure 11. Due to the nearly identical curve characteristic of the mechanical tests, it can be assumed that the joining by form fit based on a prestructuring process using the vibration welding process created a reproducible joining method for conventionally incompatible polymers. On the contrary to the state of the art $[8,9]$, condition is a dissimilar melting point of the joining partners or the ensuring of a shape 


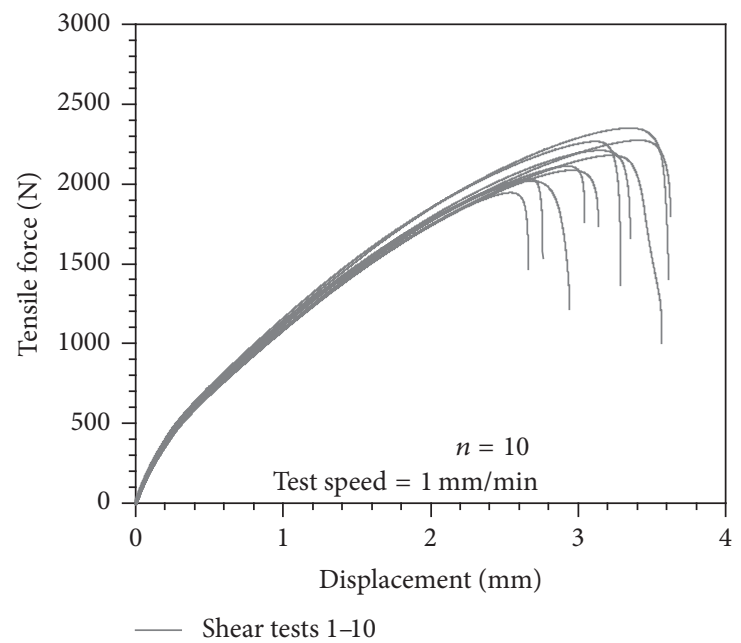

FIGURE 10: Tensile force of PA66-HDPE test specimen based on form fit, produced by prestructuring joining partner A (PA66) and subsequent welding with joining partner B (HDPE).

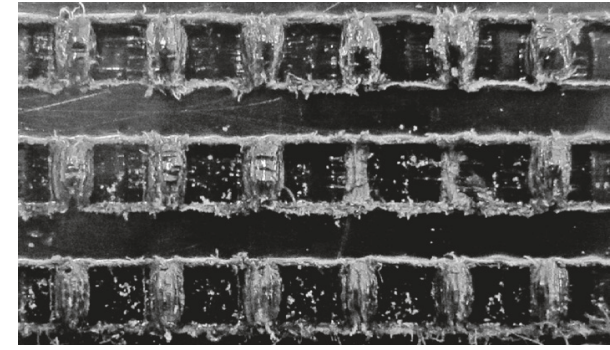

(a)

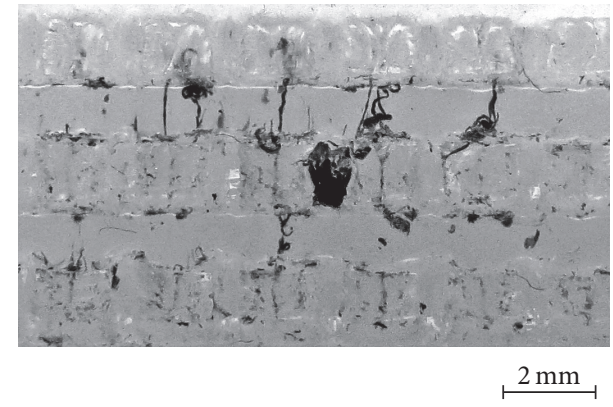

(b)

FIGURE 11: Adhesive fracture behavior of test specimen, captured by photography after mechanical test. (a) Section of joining partner A (PA66) after shear test. (b) Section of joining partner B (HDPE) after shear test.

stability of the inserted pin structures, for example, by crosslinking.

Tensile tests for unstructured welding tests could not be carried out. A failure occurred due to the bonding incompatibility of the polymers directly after the joining process without the application of a mechanical load.

\section{Conclusion}

The investigations have shown that the production of joints between bonding incompatible polymers by means of form fit using the vibration welding process is possible and results in components with reproducible shear behavior. Furthermore, we were able to demonstrate the high potential for the joining of conventionally incompatible polymer combinations by form fit with a prestructuring of one joining partner with undercut structures. This could allow for a significant expansion of the combinable polymer spectrum for friction based welding technologies, which is helpful for new applications or a further increase of the functionality of components. Furthermore, this new preconditioning method can potentially result in even higher bonding strengths values if there is additional bonding compatibility of the polymers, albeit the lower-melting component will not melt so that there is no direct molecular exchange in the welding layer.

In the usual implementation, the joining of PA66 and HDPE by welding is not possible due to the bonding incompatibility of both materials. Analysis on unstructured PA66-HDPE combinations showed a failure which occurred without the application of a mechanical load. Based on a prestructuring of the PA66 specimen and the generation of undercuts, a form fit between the PA66 and HDPE specimen could be created using vibration welding. This increased the bonding strength of the test specimen to a measurable level and, in a single case, allowed for an application of a mechanical load of up to $2350 \mathrm{~N}$ ( $2147 \mathrm{~N}$ average) to the polymer joint or, respectively, $45 \mathrm{~N}$ per single pin of the prestructure before a failure of the joint occurred.

Due to the shown high potential of the joining of with conventional methods incompatible polymer combinations by form fit based on prestructuring of one joining partner, further detailed fundamental investigations are planned. On the one hand, the interactions between the material, the process, and the prestructure as well as the resulting bond strength especially the behavior with pure tensile load of the generated undercuts perpendicular to the joining zone have 
to be analyzed. Furthermore, different structural geometries for the prestructuring and their introduction mechanism are to be examined numerically and experimentally. The investigations also have to be extended to encompass other polymer combinations and further friction based welding processes, such as ultrasonic welding.

\section{Conflicts of Interest}

The authors declare that there are no conflicts of interest regarding the publication of this paper.

\section{References}

[1] C. Hopmann and M. Weber, "New concepts for joining dissimilar thermoplastics using laser radiation," Joining Plastics, vol. 2, pp. 116-125, 2012.

[2] Deutscher Verband für Schweißen and verwandte Verfahren, "Herausforderungen an die Verbindungstechnik in Anwendungen aus Leichtbau und erneuerbaren Energien," Joining Plastics, vol. 6, pp. 99-107, 2012.

[3] G. W. Ehrenstein, Handbuch Kunststoff-Verbindungstechnik, Hanser, München, Germany, 2004.

[4] C. Bonten, Beitrag zur Erklärung des Wirkmechanismus in Schweißverbindungen aus teilkristallinen Thermoplasten [Ph.D. thesis], Universität Gesamthochschule Essen, Essen, Germany, 1998.

[5] D. A. Grewell, A. Benatar, and J. Park, Plastics and Composites Welding Handbook, Hanser, München, Germany, 2003.

[6] J. Rotheiser, Joining of Plastics-Handbook for Designers and Engineers, Hanser, München, Germany, 1999.

[7] A. Jaeger, "Kombinationen potenzieren das Leistungsvermögen-Trends, Tendenzen und Perspektiven beim Mehrkomponenten-Spritzgießen," Kunststoffe, vol. 10, pp. 91-94, 1991.

[8] J. Vetter and G. W. Ehrenstein, "Biaxial vibration welding of polypropylene," in Proceedings of the Annual Technical Conference - ANTEC, Conference Proceedings, pp. 1344-1348, New York, NY, USA, 1999.

[9] P. J. Bates, J. MacDonald, V. Sidiropoulos, and M. Kontopoulou, "Comparison of experimental and analytical vibration welding meltdown-time profiles for nylon 66 and polypropylene," Polymer Engineering and Science, vol. 45, no. 6, pp. 789-797, 2005.

[10] M. Menacher, Vibrationsschweißen von strahlenvernetztem Polyamid 66 [Ph.D. thesis], Friedrich-Alexander-Universität Erlangen-Nürnberg, Erlangen, Germany, 2015.

[11] P. Amend, S. Pfindel, and M. Schmidt, "Thermal joining of thermoplastic metal hybrids by means of mono- and polychromatic radiation," Physics Procedia, vol. 41, pp. 98-105, 2013.

[12] E. Rodríguez-Vidal, C. Sanz, C. Soriano, J. Leunda, and G. Verhaeghe, "Effect of metal micro-structuring on the mechanical behavior of polymer-metal laser T-joints," Journal of Materials Processing Technology, vol. 229, pp. 668-677, 2016.

[13] A. N. Fuchs, F. X. Wirth, P. Rinck, and M. F. Zaeh, "Lasergenerated macroscopic and microscopic surface structures for the joining of aluminum and thermoplastics using friction press joining," Physics Procedia, vol. 56, pp. 801-810, 2014.

[14] E. E. Feistauer, R. P. M. Guimarães, T. Ebel, J. F. Dos Santos, and S. T. Amancio-Filho, "Ultrasonic joining: a novel directassembly technique for metal-composite hybrid structures," Materials Letters, vol. 170, pp. 1-4, 2016.
[15] G. Lucchetta, F. Marinello, and P. F. Bariani, "Aluminum sheet surface roughness correlation with adhesion in polymer metal hybrid overmolding," CIRP Annals-Manufacturing Technology, vol. 60, no. 1, pp. 559-562, 2011.

[16] P. Mitschang, R. Velthuis, S. Emrich, and M. Kopnarski, "Induction heated joining of aluminum and carbon fiber reinforced nylon 66," Journal of Thermoplastic Composite Materials, vol. 22, no. 6, pp. 767-801, 2009.

[17] T. Kleffel and D. Drummer, "Investigating the suitability of roughness parameters to assess the bond strength of polymermetal hybrid structures with mechanical adhesion," Composites Part B: Engineering, vol. 117, pp. 20-25, 2017.

[18] V. K. Stokes, "Vibration welding of thermoplastics. Part I: phenomenology of the welding process," Polymer Engineering \& Science, vol. 28, no. 11, pp. 718-727, 1988.

[19] H. Potente, P. Michel, and B. Ruthmann, "Eine Analyse des Vibrationsschweißens," Kunststoffe, vol. 77, pp. 711-716, 1987.

[20] A. K. H. Schlarb, Zum Vibrationsschweißen von Polymerwerkstoffen [Ph.D., thesis], Universität-Gesamthochschule Kassel, Kassel, Germany, 1989. 

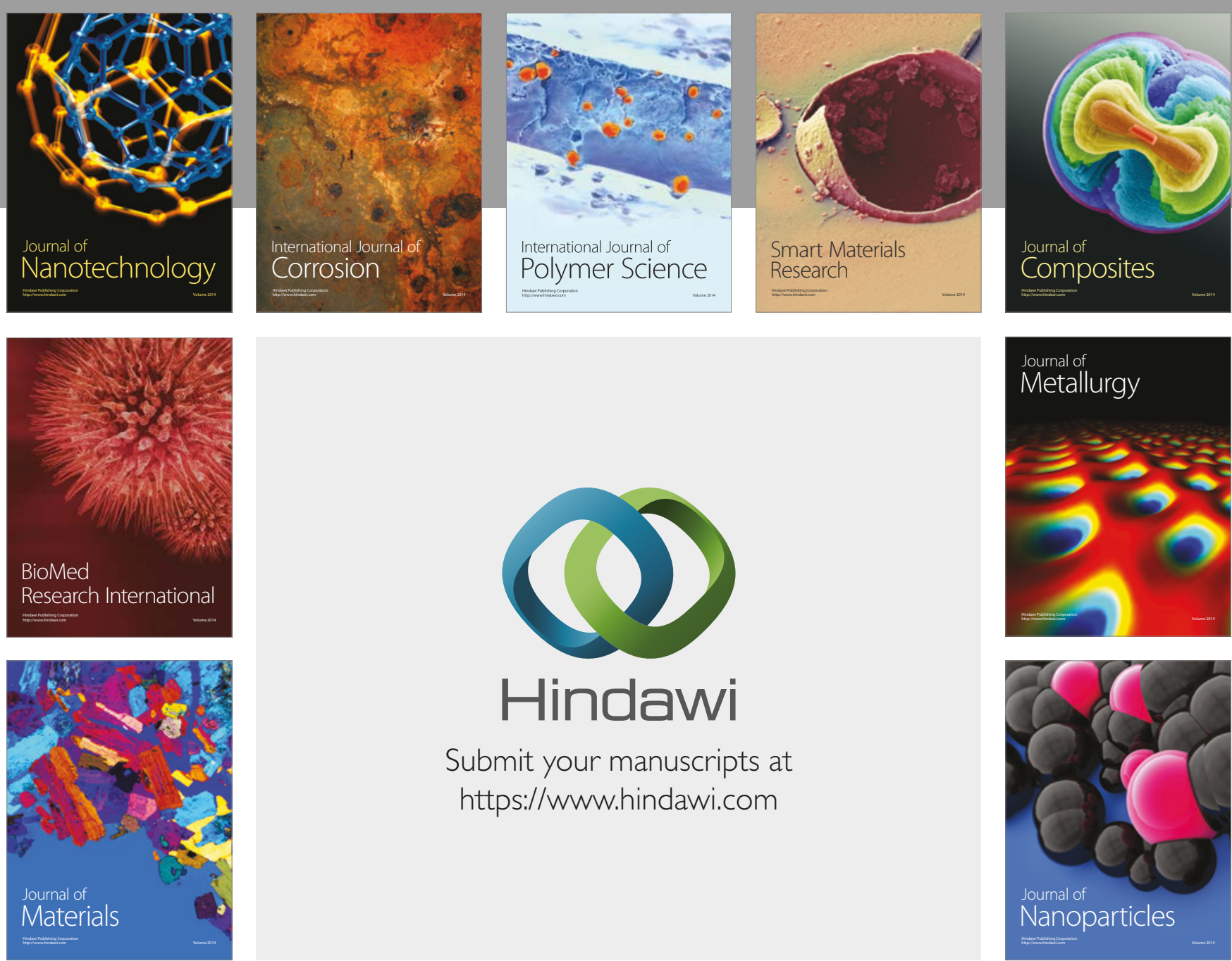

\section{Hindawi}

Submit your manuscripts at

https://www.hindawi.com
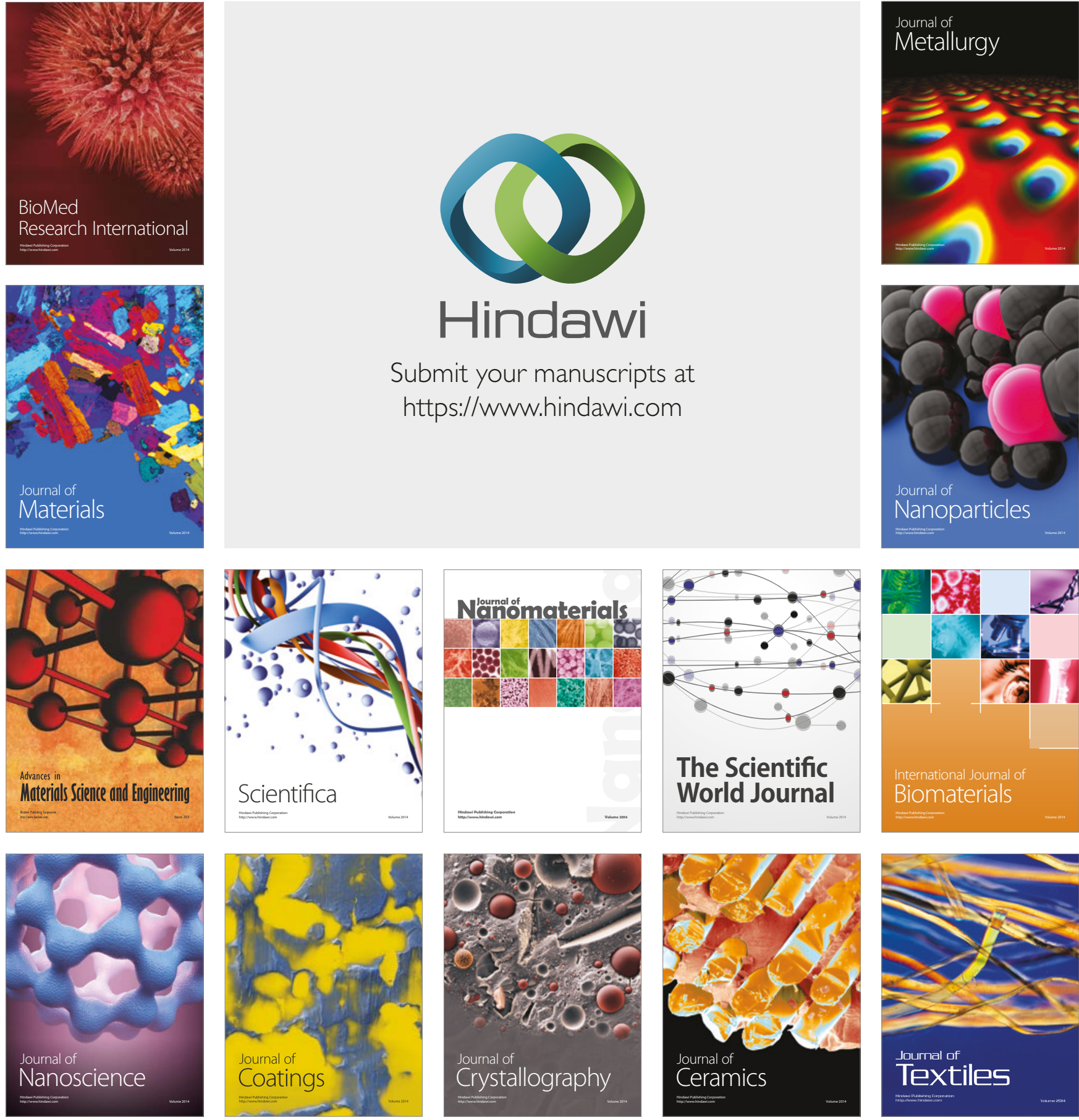

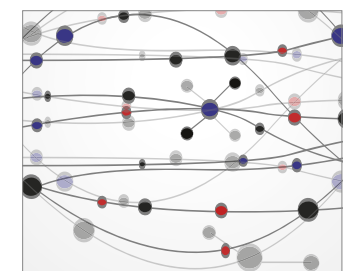

The Scientific World Journal
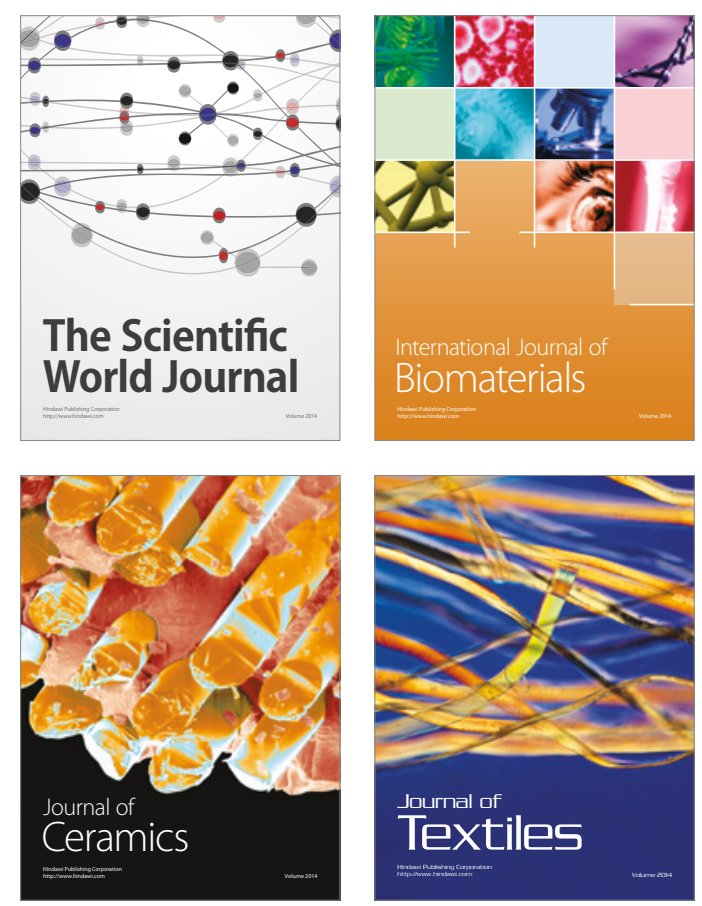